\title{
Article
}

\section{Examination of the effects of a new compression garment on skin tissue oxygenation in healthy volunteers}

Chohan, Ambreen, Haworth, Lauren, Sumner, Simon, Olivier, Mairi, Birdsall, Daniel and Whitaker, Justine Claire

Available at http://clok.uclan.ac.uk/28599/

Chohan, Ambreen ORCID: 0000-0003-0544-7832, Haworth, Lauren ORCID: 0000-0002-1718-6564, Sumner, Simon, Olivier, Mairi, Birdsall, Daniel and Whitaker, Justine Claire ORCID: 0000-0003-3885-6245 (2019) Examination of the effects of a new compression garment on skin tissue oxygenation in healthy volunteers. Journal of Wound Care, 28 (7). ISSN 0969-0700

It is advisable to refer to the publisher's version if you intend to cite from the work. 10.12968/jowc.2019.28.7.429

For more information about UCLan's research in this area go to http://www.uclan.ac.uk/researchgroups/ and search for <name of research Group>.

For information about Research generally at UCLan please go to http://www.uclan.ac.uk/research/

All outputs in CLoK are protected by Intellectual Property Rights law, including Copyright law. Copyright, IPR and Moral Rights for the works on this site are retained by the individual authors and/or other copyright owners. Terms and conditions for use of this material are defined in the policies page.

\section{CLoK}

Central Lancashire online Knowledge www.clok.uclan.ac.uk

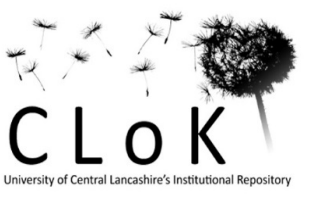




\section{ABSTRACT}

Aim: Compression systems such as bandaging and compression stockings, aim to correct venous insufficiency by counteracting the force of gravity, increasing cutaneous pressure. Compression devices have been shown to reduce venous stasis, increase blood flow and skin tissue oxygenation $\left(\mathrm{StO}_{2}\right)$, promoting healthy tissue. This quantitative study aims to explore the efficacy of a new compression garment in three sitting positions in healthy adults.

Methods: Twenty-eight participants (aged 24.6 years \pm 8.4 years; 13 Males, 15 Females) were screened and recruited using (PAR-Q, CA). All data conformed to the Declaration of Helsinki and ethical principles. Participants attended three separate one-hour sessions to evaluate $\mathrm{StO}_{2}$ in supine-lying, chair-sitting and long-sitting positions. $\mathrm{StO}_{2}$ was recorded for 20 -minutes pre-, during and post- a 20-minute intervention of the TributeWrap ${ }^{\text {TM }}$ (Lohmann-Rauscher, DE). A repeatedmeasures analysis of variance (ANOVA) was followed by post-hoc pairwise comparisons.

Results: A significant difference was seen between the three seating positions $(p=0.000)$. Chairsitting had the lowest $\mathrm{StO}_{2}$ pre-intervention, increasing $\mathrm{StO}_{2}$ significantly $(32.25 \%, \mathrm{p}=0.000)$ during wear $(24.8 \%$ higher than baseline post-intervention). No significant difference was seen between long-sitting and supine-lying $(\mathrm{p}=1.000)$. In contrast long-sitting and supine-lying $\mathrm{StO}_{2}$ was higher pre-intervention compared to the chair and only increased post-intervention $(11 \%$ and $16.8 \%$ respectively, $\mathrm{p}=0.000)$; compared to baseline.

Conclusion: This compression garment significantly increases $\mathrm{StO}_{2}$ levels in all seating positions. Increasing $\mathrm{StO}_{2}$ through short intervention sessions with this reusable device has the potential to improve self-management of tissue health in individuals with reduced mobility, oedema or venous insufficiency as well as elite athletes.

Key words: Compression garment, tissue oxygenation, tissue health, self-management, rehabilitation 


\section{Key points:}

- Position has a significant effect on tissue oxygenation and effectiveness of compression garments, which needs to be a consideration within patient centred care.

- This compression garment has positive implications for self-management of Primary lymphoedema as part of a 24-hour care plan.

- This compression garment has potential positive implications for the management of venous disease or compromise, post-surgical wounds and sedentary individuals or those with reduced mobility.

- Elite athletes may also benefit from improved tissue recovery and tissue health through use of this compression garment for post-match or post injury rehabilitation. 


\section{INTRODUCTION}

An important component in the treatment and long-term management of lymphoedema and other venous diseases is compression therapy. ${ }^{1-5}$ This allows for lymphoedema patients to self-manage their condition which is a key outcome for them. ${ }^{6,7}$ Compression therapy aims to increase the efficacy and effectiveness of both the lymphatic and venous system in moving fluid, ${ }^{2}$ either passively through the use of compression garments and bandages, or actively using intermittent pneumatic compression (IPC) devices. ${ }^{8,9}$ This is achieved by compressing the veins, thus reducing their diameter and increasing the velocity of blood flow. ${ }^{9}$ It has long been postulated that advanced venous insufficiencies may lead to increased venous pressure, allowing interstitial fluid and fibrinogen to leak through capillary pores, forming a diffusion barrier to oxygen. ${ }^{10}$ This in turn has implications for resulting oedema, ulceration and deteriorating tissue health. ${ }^{8}$ Compression hosiery increases interstitial pressure in order to enhance the reabsorption of leaked fluid (oedema), thus improving the diffusion of oxygen and overall tissue health. ${ }^{11,12}$

Compression therapy has previously demonstrated a positive impact on both calf muscle oxygenation and venous pooling whilst resting in a supine and standing position. ${ }^{11,13}$ Applying a sufficient external pressure on lower limb muscles may counteract issues related to swelling and relieve muscle fatigue related symptoms at rest. ${ }^{14}$ Increase in muscle oxygenation may be attributed to improved oxygen transportation and waste removal, ${ }^{13,15}$ positively influencing tissue health. More recently, a strong correlation $(\mathrm{R}=0.82)$ has been shown between increased compression (up to $40 \mathrm{mmHg}$ ) and higher $\mathrm{StO}_{2}$ levels. ${ }^{16} \mathrm{~A}$ key objective of managing lymphoedema/chronic oedema is that of self-management. ${ }^{17}$ Educating and empowering the patient to have greater ownership and control of their care in individualised care plans is also a key objective in NHS England Five Year Forward View. ${ }^{18}$ Up to $89 \%$ of individuals with chronic lymphoedema report an increase in night time swelling when compression is not used; suggesting an increasing number of patients are requiring night time garments as part of their 24-hour management plan. ${ }^{7,19}$ Although the data 
supporting this is based on a relatively small study, it is key as the body of knowledge in this field is limited. The impact that different compression garments have on tissue oxygenation may prove inciteful to clinical decision making for effective patient-centred care.

During the planning phase and the application of patient-care, the importance of positioning must not be overlooked. The gravitational change that occurs with change in body positioning has been shown to affect optimal blood flow and oxygen transport and is thus used as a management technique in critical care, to optimise recovery. ${ }^{20}$ Recent research analysing oxygenation saturation levels in five different body positions, suggested that upright chair sitting produced the highest levels of oxygenation, whilst supine lying produced the lowest. ${ }^{21}$ This study however considers only pulse oximetry and not the variations in lower limb tissue oxygenation that may occur with change in body position or any form of vascular compromise. ${ }^{21}$ Patient management planning must also consider whether garments afford mobilisation, as mobilisation has been seen to increase post-operative oxygen saturation thus potentially reducing tissue healing times. ${ }^{22}$

Compression garments are regularly used by athletes, as an inexpensive and convenient modality to speed up recovery time and improve performance. ${ }^{23,24}$ Many compression garment manufacturers claim to provide the wearer with enhanced blood flow, better muscle oxygenation, reduced fatigue, faster recovery, reduced muscle oscillation and reduced muscle injury, ${ }^{25}$ yet little empirical research supports this. When worn post exercise or competition, there have been exciting findings on markers of muscle damage in the literature to support the use of compression garments. ${ }^{24,26}$ During intense exercise that leads to skeletal muscle cell structure damage, there are increases in blood Creatine Kinase (CK) activity. Gill et al., ${ }^{27}$ found rugby players wearing compression garments for 12 hours after a competitive rugby match led to a substantial decrease in (CK) activity 36 and 84 hours post-match compared to a placebo garment. Due to the ease of use and relative low expense, compression garments are commonly used in professional sport. 
Athlete can wear the garments immediately post-match or in between heats, followed by overnight wear to enable them to continue their training schedule or prepare for the next game. ${ }^{27}$

In addition to considering the effects of a compression garment and differences in position, the effects skin temperature may have on the lymphatic system require consideration. A minimum clinically important difference of $0.5^{\circ} \mathrm{C}$ change in skin temperature has been suggested in the lower $\operatorname{limb}^{28}$ Literature has suggested that increased skin temperature increases lymph flow rate and protein concentration, ${ }^{29}$ however while thermotherapy has been suggested as an alternative management tool for lymphoedema, conflicting evidence exists around its true impact on lymph drainage. ${ }^{30-34}$ This study aimed to explore the effects of a new compression garment (Tributewrap ${ }^{\mathrm{TM}}$ ) on tissue oxygenation and temperature in three different sitting positions in healthy adults. Due to the padded/quilted structure of this compression garment it is important to understand whether the chevron quilted structure of this compression garment leads to an increase in tissue oxygenation through its design, or through thermal therapy and a temperature increase.

\section{METHODS}

\section{Participants}

All volunteers to the study were screened using the Physical Activity Readiness Questionnaire (PAR-Q) $)^{35}$ to check eligibility and to ensure that anyone that had a history of physiological or neuropathic conditions that could impact circulatory function or lymphatic drainage were excluded. All data collection conformed to the declaration of Helsinki and data protection principles (GDPR), volunteers gave written informed consent prior to participation. Full ethical approval was granted by the University Ethics Committee (STEMH \#566). A convenience sample of individuals was recruited through staff and students of the University and through the snowballing effects of the study. 


\section{Procedure}

\section{The device}

The Tributewrap $^{\text {TM }}$ (Lohmann-Rauscher, Wisconsin, USA; Figure 1) is an off the shelf, adjustable padded "night time" compression garment (material blend of nylon, polyurethane, polyester and spandex). The intended application of the compression garment is to allow the user to self-manage their condition independently, long term, which is a key outcome for many patients. ${ }^{6,7}$

\section{The Intervention}

All participants visited the University testing facility for three separate one-hour sessions at least 24 hours apart. At the first session for each participant, baseline anthropometric measures were taken from the right lower leg (Table 1) to size each participant according to current manufacturer guidance. Participants were then tested in one of the three positions (Chair-sitting, long sitting and supine lying), conditions were randomised over the three data collection days (www.randomization.com). Tissue Oxygenation $\left(\mathrm{StO}_{2}\right)$ was measured throughout each session continuously using a wireless Near-Infrared Spectroscopy monitor (MoXY Monitor, MN), attached to the distal popliteal region of the right calf, approximately over the fibular artery. A lightweight cloth covered the area to ensure environmental light interference was minimal. Skin temperature was taken distal to the popliteal region of the right calf at the start followed by 20,40 and 60 minutes. Tissue oxygenation was averaged over each of the three twenty-minute time periods (pre-intervention (baseline), during intervention, and post-intervention). Following the twenty-minute acclimatisation period (pre-intervention), the intervention consisted of the application of a compression garment (TributeWrap ${ }^{\text {TM }}$, Lohman-Rauscher, DE; Figure 1), this was then removed for the final 20 minutes post intervention. Each participant completed a series of questions following each session relating to comfort, sensation and potential adherence to the intervention if it was to be prescribed by a clinician. Participants were also asked to provide their preference of seating position, with justification for their choice. 


\section{Data Analysis}

All tissue oxygenation, comfort and temperature data for the three sitting positions (upright chair sitting, long-sitting, supine lying) at three different time points (pre-intervention (baseline), during, post-intervention) were statistically analysed (SPSS v25, IBM) using a repeated measured ANOVA with post-hoc pairwise comparisons with Bonferroni corrections for applicable scores (significance level $\alpha=0.05$ ). Violations of Mauchley's sphericity assumption were accounted for using the Greenhouse-Geiser correction where required to avoid a type one error.

\section{RESULTS}

This study has seen 45 individuals contact the research team for information about the study, 6 were excluded immediately as they did not meet the inclusion criteria for the study. Of the remaining participants thirty-nine completed the screening form to assess eligibility and twentyeight have been included with the remainder withdrawn due to no response. The demographic and anthropometric data for the individuals $(\mathrm{n}=28)$ are displayed in table 1.

A significant difference was seen between the three seating positions ( $p=0.000$; Figure 2). Chairsitting had the lowest $\mathrm{StO}_{2}$ pre-intervention and no significant difference was seen between longsitting and supine-lying $(\mathrm{p}=1.000)$. When chair-sitting, the garment increased $\mathrm{StO}_{2}$ significantly during the intervention $(32.25 \% ; \mathrm{p}=0.000)$ and decreased $\mathrm{StO}_{2}$ significantly in the 20 minutes following the intervention $(5.6 \% ; \mathrm{p}=0.000)$; yielding an overall $24.8 \%$ increase from baseline to post-intervention. In contrast long-sitting and supine-lying did not increase $\mathrm{StO}_{2}$ during the intervention, but increased $\mathrm{StO}_{2}$ significantly $(\mathrm{p}=0.000)$ when comparing post-intervention with the pre-intervention baseline (11\%-16.8\% respectively; See table 2$)$.

During the course of the intervention, skin temperature was monitored at each 20-minute interval to ascertain whether there was a significant change, as it was hypothesised that a temperature change could occur due to the device having a quilted enclosed structure for the lower leg and 
foot. Whilst statistical analysis showed that temperature increased significantly during wear of the compression garment, this change was less than the $0.5^{\circ}$ change required to be clinically important. ${ }^{28}$

It is evident from the tissue oxygenation data that individuals responded distinctly different to the three seating positions. Of the three sitting positions the upright chair-sitting was the sole position in which tissue oxygenation continued to significantly rise during the intervention ( $32 \%$ increase), moderately declining post intervention by $5.6 \%$. Both long-sitting and supine-lying did not significantly alter during the intervention, but improved tissue oxygenation significantly following use with supine-lying showing the biggest change from baseline $(16.8 \%)$.

\section{Subjective Feedback}

Of the twenty-eight participants, eleven (39\%) preferred the supine lying position, nine $(32 \%)$ preferred long-sitting and eight $(29 \%)$ preferred being chair seated. Reasoning for the preference of supine lying included being in a more relaxed, cosy and comfortable position that led to full body relaxation and no numbness in the sacral area due to prolonged seating. Feedback suggested all participants believed the compression garment provided similar perceived comfort irrespective of seating position and were also highly likely to use it regularly if it was to be prescribed for their use by a clinician.

\section{DISCUSSION}

This study explored the effects of a new compression garment on skin tissue oxygenation and temperature in three different sitting positions in a group of healthy adults. The data from this study looked to establish temperature and tissue oxygenation levels pre-intervention(baseline), during and post intervention with a new compression garment.

When comparing oxygenation saturation levels in healthy individuals, previous research has shown that the upright chair sitting position produced the highest oxygen saturation levels and the supine 
lying position produced the lowest. ${ }^{21}$ In contrast to this, the present study suggests that both the supine-lying and long-sitting positions afford higher $\mathrm{StO}_{2}$ levels than chair sitting, at baseline resting stance. Previous research however did not consider body temperature or carryover effects of change in body position. ${ }^{21}$ Furthermore, the influence of gravitational effects of body position were seen to be different in the present study for the three seating positions during the compression garment intervention. Whilst the supine-lying and long-sitting positions did not significantly influence tissue oxygenation during the intervention, a significant increase in $\mathrm{StO}_{2}$ was seen post intervention. It may be expected that the longer term gravitational effects of upright chair sitting may negatively impact tissue oxygenation in individuals with vascular compromise. ${ }^{36}$ However, the results of the present study suggest that the compression garment significantly increased $\mathrm{StO}_{2}$ during use (32.25\% increase from baseline), maintaining this at (24.81\% higher than baseline) 20-minutes post-compression. This therefore suggests that the garments unique foam filled, chevron design was able to work more effectively against gravity when in the chair sitting position, whilst also maintaining an improvement in supine-lying and long-sitting. It is therefore notable that this device has clear clinical potential for multiple patient groups, to improve tissue health irrespective of patient mobility issues, neuropathy, sleep position or sedentary lifestyle. However, as previous research has also alluded that patient mobilisation positively impacts postoperative oxygenation; further research is required to understand the true effect of this garment when a patient is mobilised. ${ }^{22}$

Whilst there has been wide suggestion that 24-hour care plan and self-management are key to successful health outcomes for lymphoedema patients, very little consideration has been given to use of night compression, with clinical practice varying widely in advice given for overnight management.$^{7,19,37-38}$ The present study is novel in that limited research in the effects of increasing $\mathrm{StO}_{2}$ through compression garment use exists. It should thus form the basis of further investigation in this field as it is known that a lack of oxygen in the tissues is detrimental to the cell function and general long-term deterioration of the subcutis and microvascular performance., 8-12 
The material properties of the compression garment may be thought to impact blood flow through thermoregulation. However, the results of the present study suggest that a minimum clinically important difference is not attained in skin temperature change in any seating position, between baseline and post-intervention. ${ }^{28}$ It is therefore suggested that the impact of the compression garment may predominantly be attributed to compression as opposed to thermal change due to compression garment properties.

This study has been performed with screened healthy volunteers and gives an insight into baseline $\mathrm{StO}_{2}$ levels in three different seating positions. This can further be built upon by analysing specific patient groups such as individuals with lymphoedema, venous leg ulcers, vascular compromise and reduced mobility in various clinical presentations. The results also provide a baseline for further investigation in elite athletes and recovery time.

The increase in $\mathrm{StO}_{2}$ seen in the present study, could potentially have positive effects on the recovery process post-match or competition in professional/semi-professional sport. As increased oxygen saturation may facilitate removal of fatigue markers from the muscles, especially CK levels. ${ }^{27,39}$ In addition, there is a possibility that the compression garment may be useful for sports recovery or in recovery following intense sporting activities. ${ }^{15,24}$ Further research however is needed in these groups to determine the true efficacy and effectiveness of the garment. Consideration in further work should not only be given to patient groups but also healthy athletic populations where early management may lead to improved tissue recovery and healing or prevention of venous disease or oedema in future. Long travel times on a coach or train in the seated position may present an ideal opportunity to begin the recovery process. The seated position in this study showed the highest increase in tissue oxygenation which could potentially be easily and inexpensively administered by professional athletes during long post-match travel.

Sport can place large demands on calf musculature (i.e running, endurance sports, sprinting, football, rugby, and jumping disciplines). Compression has been linked to enhancing the 'muscle 
pump' allowing blood return to the heart for removal of waste products. ${ }^{15,23}$ Following calf/soleus injury, compression garments may offer improved tissue healing throughout the rehabilitation period. Increased tissue oxygenation and hypothesised perfusion help promote tissue healing, thus delivering growth factors and increased $\mathrm{StO}_{2}$ to the healing muscle. Increased blood flow to the muscle may enhance recovery by increasing glucose offload at the muscle, aerobic resynthesis of Adenosine Tri-Phosphate (ATP) or enhanced removal of waste and cellular breakdown products. ${ }^{40}$

\section{CONCLUSION}

In conclusion, this study suggests that use of this new compression garment, increases tissue oxygenation saturation levels in all three seating positions, with higher tissue oxygenation levels seen in supine-lying and long-sitting, but the greatest increase seen in the upright chair-sitting position. The findings from this study have potential implications as a self-management tool for individuals with lymphoedema, venous disease or compromise, sedentary patients (including those traveling for long periods), individuals with reduced mobility or elite athletes. As this study focused on identifying the effects of this compression garment in healthy individuals to evaluate the potential impact, further studies are required with these groups to determine true efficacy and effectiveness. The further study of the impact of a range of compression garments and their effects on tissue oxygenation in different positions, both sedentary and dynamic, may help to identify a potential ladder of intervention to aid clinical decision making. 


\section{REFERENCES:}

1. Cooper, G. Compression therapy and the management of lower-limb lymphoedema: the male perspective. British journal of community nursing. 2015; 20: 3, $118-124$.

2. Green, T. Compression systems used in lymphoedema management. British journal of nursing. 2018; 27: 20, $1150-1152$.

3. Kalodiki, E., Ellis, M., Kakkos, S.K. et al. Immediate hemodynamic effect of the additional use of the SCD Express ${ }^{\mathrm{TM}}$ compression system in patients with venous ulcers treated with the four-layer compression bandaging system. European Journal of Vascular and Endovascular Surgery. 2007; 33: 483-487

4. Felty, C., Rooke, T., Compression therapy for chronic venous insufficiency. Seminars in Vascular Surgery. 2005; 18: 36-40

5. Chiang, N., Rodda, O., Oldham, S., et al. Effects of compression therapy and venous surgery on tissue oxygenation in chronic disease. Phlebology. 2019; 0: 0, 1-7.

6. Kapp S, Miller C. The experience of self-management following venous leg ulcer healing. Journal of clinical nursing. 2014; 24: $9-10,1300-1309$.

7. Bertsch T. Evaluation of a novel night-time compression garment: a prospective observational study. British journal of community nursing. 2018; 23: 11, $535-541$.

8. Kumar, S., Walker, M. The effects of intermittent pneumatic compression on the arterial and venous systems of the lower limb: a review. Journal of Tissue Viability. 2002; 12: 58-62.

9. Liu R, Lao, T.T, Kwok Y.L, Li Y et al. Effects of graduated compression stockings with different pressure profiles on lower-limb venous structures and haemodynamics. Advances in therapy. 2008; 25: 5, $465-478$.

10. Wolff, O., Wentel, T., Reeder, S., Neumann, H. The effects of compression ulcer stockings on the capillary filtration rate and the formation of edema. Phlebologie. 2011; 40:5, 245-250. 
11. Agu, O., Baker, D., Seifalian, A. Effect of graduated compression stockings on limb oxygenation and venous function during exercise in patients with venous insufficiency. Vascular. 2004; 12: 1, 69-76.

12. Brinkmann, C., Hermann, R., Ruhl, E., et al. Effects of wearing compression stockings on the physical performance of T2DM Men with MetS. International Journal of Sports Medicine. 2016; 37: 347-353.

13. Bringard A, Denis R, Belluye N, Perrey S. Effects of compression tights on calf muscle oxygenation and venous pooling during quiet resting in supine and standing positions. Journal of sports medicine and physical fitness. 2006; 46: 4, 548 - 554

14. Partsch, H., Winiger, J., Lun, B. Compression stockings reduce occupational leg swelling. Dermatologic Surgery. 2004; 30: 5, 737-743.

15. Kraemer, W., Flanagan, S., Comstock, B., et al. Effects of a whole-body compression garment on markers of recovery after a heavy resistance workout in men and women. Journal of Strength and Conditioning Research. 2010; 23: 804-814.

16. Dermont T, Morizot I, Bouhaddi M, Menetrier A. Changes in tissue oxygen saturation in response to different calf compression sleeves. Journal of sports medicine 2015; 2015: 1 5.

17. Commissioning Guidance for Lymphoedema Services for Adults in the United Kingdom. (2019). National Lymphoedema Partnership NLP, March 2019.

18. NHS England (2014) Five Year Forward View. October 2014. Available from https://www.england.nhs.uk

19. Whitaker, J. Lymphoedema management at night: views from patients across five countries. British journal of clinical nursing. 2016; 21: 22-30.

20. Jones A.Y.M, Dean E. Body position change and its effect on hemodynamic and metabolic status. Heart and lung. 2004; 33: 5, 281 - 290. 
21. Ceylan B, Khorshid L, Gunes U.K, Zaybak A. Evaluation of oxygen saturation values in different body positions in healthy individuals. Journal of clinical nursing. 2016; 25: 7, 1095 $-1100$.

22. Mynster, T., Jensen, M., Jensen, F., et al. The effect of posture on late postoperative oxygenation. Anaesthesia. 1996; 51: 225-227.

23. Bringard, A., Belluye, N., Perrey, S. Aerobic energy cost and sensation responses during submaximal running exercise - positive effects of wearing compressions tights. International journal of sports medicine. 2006; 27: 5, 373-378.

24. Born, D., Sperlich, B., Holmberg, H. Bringing light into the dark: effects of compression clothing on performance and recovery. International journal of sports physiology and performance. 2013; 8: 4-18.

25. Troynikov O, Ashayeri E, Burton M. et al. Factors influencing the effectiveness of compression garments used in sports. 8th Conference of the International Sports Engineering Association (ISEA), Procedia Engineering 2010; 2: 2, 2823- 2829.

26. Kraemer, W., Volek, J., Bush, J., et al. Influence of compression hosiery on physiological responses to standing fatigue in women. Medicine and science in sports and exercise journal. 2000; 32, 1849-1858.

27. Gill N.D, Beaven C.M, Cook C. Effectiveness of post-match recovery strategies in rugby players. British journal of sports medicine 2006; 40: 3, 260-264.

28. Selfe J, Whitaker J, Hardaker N. A narrative literature review identifying the minimum clinically important differences for skin temperature asymmetry at the knee. Thermology international 2008; 18: 2, 51-54.

29. Baker, P. Is there a role for contrast hydrotherapy? A Clinical Review. Journal of Lymphoedema. 2011; 6: 2, 72-80. 
30. Mariana V.F, de Fatima G.G.M, Maria Pde G. The effect of mechanical lymph drainage accompanied with heat on lymphedema. Journal of research in medical science 2011; 16: $11,1448-1451$.

31. van der Veen, P., Kempenaers, F., Vermijlen, S., et al. Electromagnetic diathermia: a lymphoscintigraphic and light reflection rheographic study of leg lymphatic and venous dynamics in healthy subjects. Lymphology. 2000; 33: 1, 12-18.

32. Ohkuma, M. Treatment of peripheral lymphedema by concomitant application of magnetic fields, vibration and hyperthermia: a preliminary report. Lymphology. 2002; 35: 87-90.

33. Campisi, C., Boccardo, F., Tacchella, M. Use of thermotherapy in management of lymphedema: clinical observations. International Journal of Angiology. 1999; 8: 73-75.

34. Solari, E., Marcozzi, C., Negrini, D., Moriondo, A. Temperature-dependent modulation of regional lymphatic contraction frequency and flow. Vascular biology and microcirculation. 2017; 313: 5, $459-483$.

35. Warbuton, D., Jamnik, V., Bredin, S., Gledhill, N. 2018 PAR-Q +. The physical activity readiness questionnaire for everyone. Heal Fit J Canada. 2018; 4: 2: 4-7.

36. NICE Guideline (NG89). Venous thromboembolism in over 16s: reducing the risk of hospital-acquired deep vein thrombosis or pulmonary embolism. 2018 https://www.nice.org.uk/guidance/ng89. (accessed 1 February 2019).

37. International Lymphoedema Framework.2012. Compression therapy: a position document on compression bandaging. $2^{\text {nd }} \quad$ edn. https://www.lympho.org/wpcontent/uploads/2016/03/Compression-bandaging-final.pdf (accessed 1 February 2019)

38. Hibbard, J., Greene, J. What the evidence shows about patient activation: better health outcomes and care experiences; fewer data on costs. Health Affairs. 2013; 32: 2, 207-214.

39. Duffield, R., Portus, M. Comparison of three types of full-body compression garments on throwing and repeat-sprint performance in cricket players. British Journal of Sports Medicine. 2007; 41: 409-414 
40. Hamlin, M., Mitchell, C., Ward, F., et al. Effects of compression garments on short term recovery of repeated sprints $3 \mathrm{~km}$ running performance in professional rugby union players. Journal of Strength and Conditioning Research. 2012; 26: 11, 2975-2982. 
Table 1: Participant demographics and anthropometrics

\begin{tabular}{|c|c|c|}
\hline DEMOGRAPHICS & MEAN (SD) & RANGE \\
\hline AgE (YEARS) & $24.6(8.3)$ & $18-48$ \\
\hline HEIGHT (M) & $1.70(0.08)$ & $1.52-1.88$ \\
\hline WEIGHT (KG) & $71.2(11.7)$ & $42.5-97.3$ \\
\hline $\mathrm{BMI}\left(\mathrm{KG} / \mathrm{M}^{2}\right)$ & $24.5(3.7)$ & $18.4-33.7$ \\
\hline GENDER & \multicolumn{2}{|c|}{15 Females; 13 Males } \\
\hline $\begin{array}{c}\text { ANKLE CIRCUMFERENCE (CM) } \\
\text { MEASURED AROUND THE JOINT } \\
\text { ABOVE THE MALLEOLI }\end{array}$ & $21.7(1.8)$ & $18.8-25.5$ \\
\hline $\begin{array}{c}\text { CALF CIRCUMFERENCE (CM) } \\
\text { MEASURED AROUND THE GREATEST } \\
\text { CIRCUMFERENCE }\end{array}$ & $36.1(4.4)$ & $22.7-45.0$ \\
\hline $\begin{array}{c}\text { CALF LENGTH (CM) } \\
\text { HEAD OF FIBULA TO LATERAL } \\
\text { MALLEOLUS }\end{array}$ & $39.4(4.2)$ & $32.5-49.0$ \\
\hline $\begin{array}{c}\text { FOOT LENGTH }(\mathrm{CM}) \\
\text { HEEL TO TIP OF HALLUX }\end{array}$ & $23.9(1.7)$ & $21.0-27.5$ \\
\hline $\begin{array}{c}\text { FOOT CIRCUMFERENCE (CM) } \\
\text { MEASURED AROUND THE GREATEST } \\
\text { FOREFOOT GIRTH }\end{array}$ & $22.6(1.7)$ & $19.0-25.0$ \\
\hline
\end{tabular}

Table 2: Tissue oxygenation $\left(\mathrm{StO}_{2}\right)$ and temperature data:

\begin{tabular}{|c|c|c|c|}
\hline & CHAIR & LONG-SITTING & SUPINE-LYING \\
\hline \multicolumn{4}{|c|}{ RAW DATA $\left(\mathrm{StO}_{2}\right)$} \\
\hline $\begin{array}{c}\text { BASELINE } \\
(20 \text { MINUTES) }\end{array}$ & $56.63(14.39)$ & $75.98(10.29)$ & $76.04(10.41)$ \\
\hline $\begin{array}{c}\text { DURING } \\
\text { INTERVENTION } \\
\text { (20 MINUTES) }\end{array}$ & $78.87(10.31)$ & $76.10(10.02)$ & $73.55(9.23)$ \\
\hline $\begin{array}{c}\text { POST- } \\
\text { INTERVENTION } \\
\text { (20 MINUTES) }\end{array}$ & $74.43(12.65)$ & $84.49(8.58)$ & $85.89(5.96)$ \\
\hline \multicolumn{4}{|c|}{ PERCENTAGE CHANGE IN $\mathrm{StO}_{2}$} \\
\hline BASELINE - DURING & $32.25^{\mathrm{A}}$ & 0.15 & -3.28 \\
\hline DURING - POST & $-5.63^{A}$ & $11.03^{\mathrm{A}}$ & $16.79^{\mathrm{A}}$ \\
\hline $\begin{array}{c}\text { OVERALL } \\
\text { (BASELINE-PosT) }\end{array}$ & $24.81^{\mathrm{A}}$ & $11.19^{\mathrm{A}}$ & $12.96^{\mathrm{A}}$ \\
\hline \multicolumn{4}{|c|}{ RAW DATA (TEMPERATURE ${ }^{\circ} \mathrm{C}$ ) } \\
\hline $\begin{array}{c}\text { BASELINE } \\
\text { (20 MINUTES) }\end{array}$ & $36.25(0.32)$ & $36.52(0.32)$ & $36.55(0.38)$ \\
\hline $\begin{array}{c}\text { DURING } \\
\text { INTERVENTION } \\
\text { (20 MINUTES) }\end{array}$ & $36.47(0.26)$ & $36.73(0.34)$ & $36.72(0.36)$ \\
\hline $\begin{array}{c}\text { PosT- } \\
\text { INTERVENTION } \\
\text { (20 MINUTES) }\end{array}$ & $36.27(0.31)$ & $36.77(0.34)$ & $36.85(0.39)$ \\
\hline
\end{tabular}


Figure 1: The compression device (TributeWrap ${ }^{\mathrm{TM}}$; Lohmann \& Rauscher, DE)

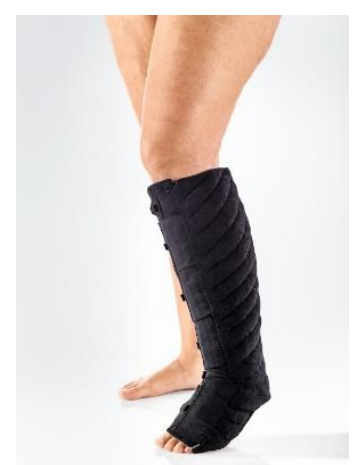

Figure 2: Tissue oxygenation in the three positions.

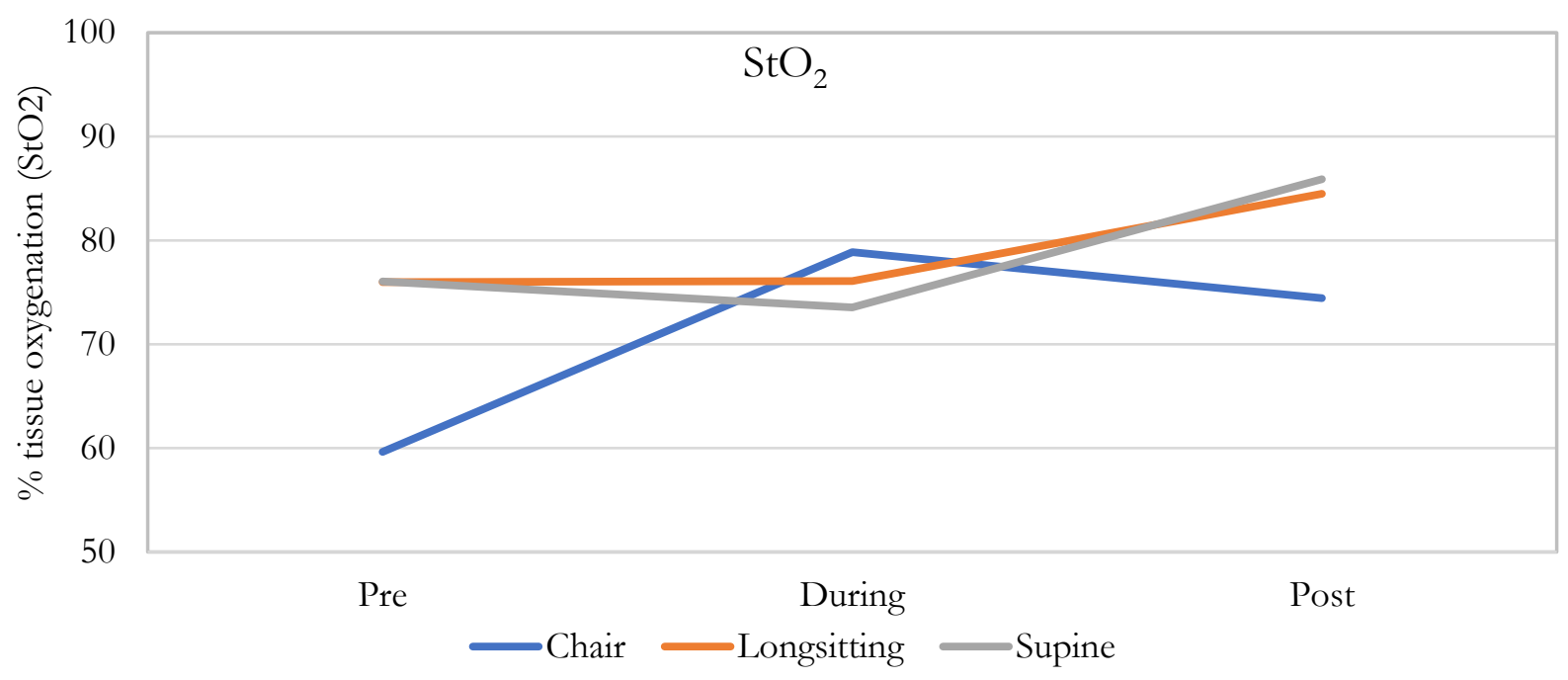

